\title{
Study of a Naturally Drying Lacquer Hybridized with Organic Silane
}

\author{
Rong Lu, Takayuki Honda, Takahisa Ishimura, and Tetsuo MiYaKOSHI ${ }^{\dagger}$ \\ Department of Industrial Chemistry, School of Science and Technology, Meiji University, \\ 1-1-1 Higashi-Mita, Tama-ku, Kawasaki 214-8571, Japan
}

(Received December 1, 2004; Accepted January 5, 2005; Published April 15, 2005)

\begin{abstract}
An organic-inorganic hybrid condensate formed by the reaction of lacquer sap and organic functional silane was examined to develop a naturally drying lacquer. The hydroxyl group of urushiol contained in the lacquer sap underwent alcoholysis reaction with the organic functional silane and generated a high molecular weight polymer of polysiloxane. The natural drying process of the hybrid lacquer film is a hydrolysis reaction. In addition, the activities of the alkoxy groups in the organic functional silane showed that the methoxy activity was higher than ethoxy, and trimethoxy activity was higher than dimethoxy. The amino residues in organic functional silane react with the cathechol ring of urushiol, and then the hybrid oxidizes to a dark color. However, there is a tendency for the ring-opening reduction of an epoxy group to produce a light color due to the coexistence of epoxy silane.

[DOI 10.1295/polymj.37.309]

KEY WORDS Hybrid / Lacquer / Organic Functional Silane / Cathecol /
\end{abstract}

Lacquers are made from the sap of lacquer trees that grow in Asian countries, such as Rhus vernicifera (China, Japan and Korea), Rhus succedanea (Vietnam) and Melanorrhoea usitate (Thailand and Cambodia), ${ }^{1}$ and are named according to their place of production. ${ }^{2}$ Lacquer film is very durable and has a beautiful appearance. Furthermore, lacquer is a material that is ecologically friendly to the earth's environment. However, because the drying process of lacquer is based on enzyme polymerization, it requires strict management of temperature and relative humidity. Also, the long time required to reach full dryness has prevented the use of lacquer as an industrial paint.

However, recently, research and development of a complex organic-inorganic polymer similar to a new frame structure, a substituted organic group, and progress in organic functional silane have expanded its use as an eco-logically friendly industrial material..$^{3-5}$

In this study, we examined organic-inorganic composite materials formed by the sol-gel reaction of urushiol and an organic functional silane in lacquer sap and found that lacquer sap hybridized with organic functional silane has a natural drying property in an environment with low relative humidity and temperature.

\section{EXPERIMENTAL}

\section{Kurome Lacquer and Organic Silane}

The raw lacquer was the sap of a Chinese lacquer tree in Chengkou, produced in the year 2000, in the Hubei province of China, and purchased from Tohityu-Urushi-Ya in Osaka, Japan. Kurome process- ing of the raw lacquer was carried out in our laboratory as follows: raw lacquer sap $(20 \mathrm{~g})$ was stirred in an open vessel (bottom diameter, $80 \mathrm{~mm}$; capacity, 100 $\mathrm{mL}$ ) at room temperature for about one and a half hours, and the temperature was then increased from 20 to $40^{\circ} \mathrm{C}$ for $2-4 \mathrm{~h}$ until the water concentration was reduced to $3-5 \% .^{6}$ The foreign matter was removed, and a $2.5 \%$ heating loss had occurred. The acetone-soluble material was $86.8 \%$, acetone in-soluble, water-soluble material was $7.9 \%$, and the acetoneand water-in-soluble material was $2.8 \%$. This kurome lacquer was used in this study.

Because an organic silicone compound that has chlorine and a mercapto radical could possibly weaken the activity of the laccase, ${ }^{7,8}$ we selected ten kinds of silane without a chlorine and/or mercapto residues, as shown in Table I.

\section{Measurement of Drying}

The hybrid lacquer produced by the reaction between kurome lacquer and an organic functional silane was dried at $20-25^{\circ} \mathrm{C}$, and $70-75 \%$ relative humidity and $20-25^{\circ} \mathrm{C}$, and $45-50 \%$ relative humidity using an automatic drying time recorder (TaiYu Equipment Co., Ltd., Osaka, Japan). The thickness of the lacquer films tested was $76 \mu \mathrm{m}$. The lacquer drying process can be divided into three steps: dust-free dry (DF), touch-free dry (TF), and hardened dry (HD) in the automatic drying time recorder. The time until needle marks appear on the glass sheet is equivalent to DF, the time until the needle marks appear on the lacquer film surface is equivalent to TF, and the time until the

${ }^{\dagger}$ To whom correspondence should be addressed (E-mail: miya@isc.meiji.ac.jp). 


\section{R. LU et al.}

Table I. Kinds of organic functional silane ${ }^{9}$

\begin{tabular}{|c|c|c|c|}
\hline No. & Classification & Chemical name & Chemical structure \\
\hline S-1 & Vinyl silane & Vinyltriethoxysilane & $\mathrm{CH}_{2}=\mathrm{CHSi}\left(\mathrm{OC}_{2} \mathrm{H}_{5}\right)_{3}$ \\
\hline$S-2$ & Amino silane & $\gamma$-Aminopropyltriethoxysilane & $\mathrm{H}_{2} \mathrm{~N}\left(\mathrm{CH}_{2}\right)_{3} \mathrm{Si}\left(\mathrm{OC}_{2} \mathrm{H}_{5}\right)_{3}$ \\
\hline$S-3$ & Amino silane & $\begin{array}{l}N \text { - }(\beta \text {-aminoethyl })-\gamma \text {-amino } \\
\text { propyltrimethoxysilane }\end{array}$ & $\mathrm{H}_{2} \mathrm{~N}\left(\mathrm{CH}_{2}\right)_{2} \mathrm{NH}\left(\mathrm{CH}_{2}\right)_{3} \mathrm{Si}\left(\mathrm{OCH}_{3}\right)_{3}$ \\
\hline S-4 & Amino silane & $\begin{array}{l}N \text { - }(\beta \text {-aminoethyl })-\gamma \text {-amino } \\
\text { propylmethyldimethoxysilane }\end{array}$ & $\left.\right|_{\mathrm{H}_{2} \mathrm{~N}\left(\mathrm{CH}_{2}\right)_{2} \mathrm{NH}\left(\mathrm{CH}_{2}\right)_{3} \mathrm{Si}\left(\mathrm{OCH}_{3}\right)_{2}} ^{\mathrm{CH}_{3}}$ \\
\hline S-5 & Epoxy silane & $\begin{array}{l}\gamma \text {-Glycidoxypropyl } \\
\text { trimethoxysilane }\end{array}$ & $\overbrace{/}^{\mathrm{CH}_{2}-\mathrm{CHCH}_{2} \mathrm{O}\left(\mathrm{CH}_{2}\right)_{3} \mathrm{Si}\left(\mathrm{OCH}_{3}\right)_{3}}$ \\
\hline S-6 & Epoxy silane & $\begin{array}{l}\gamma \text {-Glycidoxypropylmethyl } \\
\text { dimethoxysilane }\end{array}$ & $\left.\right|_{\mathrm{CH}_{2}-\mathrm{CHCH}_{2} \mathrm{O}\left(\mathrm{CH}_{2}\right)_{3} \mathrm{Si}\left(\mathrm{OCH}_{3}\right)_{2}} ^{\mathrm{CH}_{3}}$ \\
\hline S-7 & Epoxy silane & $\begin{array}{l}\beta \text {-(3,4-Epoxycylohexyl)-ethyl } \\
\text { trimethoxysilane }\end{array}$ & $\mathrm{I}_{4} \mathrm{Si}(\mathrm{OCH}$ \\
\hline S-8 & Acryl silane & $\begin{array}{l}\gamma \text {-Methacryloxypropyl } \\
\text { trimethoxysilane }\end{array}$ & $\mathrm{CH}_{2}=\mathrm{C}-\mathrm{C}-\mathrm{O}\left(\mathrm{CH}_{2}\right)_{3} \mathrm{Si}\left(\mathrm{OCH}_{3}\right)_{3}$ \\
\hline S-9 & Acryl silane & $\begin{array}{l}\gamma \text {-Methacryloxypropyl } \\
\text { methyldimethoxysilane }\end{array}$ & $\left.\left.\right|_{\mathrm{CH}_{2}=\mathrm{C}-\mathrm{C}-\mathrm{C}\left(\mathrm{CH}_{2}\right)_{3} \mathrm{Si}\left(\mathrm{OCH}_{3}\right)_{2}} ^{\mathrm{CH}_{3}}\right|_{\mathrm{O}} ^{\mathrm{CH}_{3}}$ \\
\hline S-10 & Phenyl silane & Phenyltrimethoxysilane & $\mathrm{i}\left(\mathrm{OCH}_{3}\right)_{3}$ \\
\hline
\end{tabular}

needle marks on the lacquer film surface disappear completely is equivalent to HD. ${ }^{10,11}$

\section{Measurement of $\mathrm{pH}$}

Although a preliminary value can be acquired even if the glass electrode of a $\mathrm{pH}$ meter ( $\mathrm{LAB} \mathrm{pH}$ meter F21 , Horiba, Japan) is inserted directly into the liquid raw lacquer, the low water concentration of lacquer makes the $\mathrm{pH}$ of kurome lacquer difficult to measure directly. Therefore, we used a mixture of acetone and distilled water (acetone:water $=2: 8$ ) as a solvent to measure the $\mathrm{pH}$ of the kurome lacquer. One gram of lacquer sap was dissolved in $10 \mathrm{~g}$ of the mixed solvent, and the mixture was stirred with ultrasonic mixer for $10 \mathrm{~min}$. The $\mathrm{pH}$ of the filtrate was regarded as the $\mathrm{pH}$ of the original lacquer.

\section{Measurement of Viscosities}

The viscosities of lacquer saps were determined at room temperature with a Brookfield programmable DV-II+ viscometer (Brookfield Engineering Labora- tories, Inc.). The spindle was a CPE-51, the rotation speed was from 5-20 rpm, and the measurement sample was $0.5 \mathrm{~mL}$.

\section{Measurement of $M_{W}$}

Molecular weights of the lacquer saps were determined at $40^{\circ} \mathrm{C}$ by aqueous phase GPC (column: Tosoh, TSK-gel, $\alpha-3000, \alpha-4000$, and $\alpha-\mathrm{M}, \phi 7.8 \mathrm{~mm} \times$ $300 \mathrm{~mm} \times 3$; eluent, DMF with $0.01 \mathrm{M} \mathrm{LiBr}$ ) running on an HPLC system with an RI detector using polystyrene standards having molecular weights of $5.00 \times$ $10^{2}, 2.63 \times 10^{3}$, and $1.81 \times 10^{4}$. The elution rate and pressure of the DMF eluent were $0.8 \mathrm{~mL} / \mathrm{min}$ and 48 $\mathrm{kgf} / \mathrm{cm}^{2}$. Molecular weights less than or equal 36000 Da were consider to be polymers $\left(M_{\mathrm{W}} \leqq 36000\right)$, $3000 \geqq M_{\mathrm{W}} \geqq 640$ to be dimers or oligomers, and $M_{\mathrm{W}}=316-320$ to be monomers.

\section{Measurement of IR}

Infrared spectra were taken on a JASCO FTIR460+ spectrometer. Because it is possible that the 
moisture in the lacquer sap would melt a $\mathrm{KBr}$ or $\mathrm{NaCl}$ disk, a polyvinylidene chloride film (Saran wrap, Asahi Kasei, Japan) was used to form the IR sample. The lacquer sap was thinly applied with a spatula on the polyvinylidene film, and the same kind of polyvinylidene chloride film was used as a blank. Measurements ranged from 500 to $4000 \mathrm{~cm}^{-1}$, at a resolution of $2 \mathrm{~cm}^{-1}$, and were carried out with 16 additions.

\section{RESULTS AND DISCUSSION}

\section{Drying Properties of Lacquer Hybridized with Silane}

The organic silicone compound ( $2 \mathrm{wt} \%$ ) was added to the kurome lacquer sap as shown in Table I and stirred at $250 \mathrm{rpm}$ for $30 \mathrm{~min}$. The hybrid lacquers were formed into films $76 \mu \mathrm{m}$ thick and were dried at $20-25^{\circ} \mathrm{C}$ and $70-75 \%$ relative humidity or $20-25^{\circ} \mathrm{C}$ and $45-50 \%$ relative humidity using an automatic drying time recorder. The results are summarized in Table II.

S-3 amino silane and S-7 epoxy silane increased the drying speed of the lacquer. Lacquer hybridized with S-3 and S-7 dried within $24 \mathrm{~h}$ even at $20-25^{\circ} \mathrm{C}$ and $45-50 \%$ relative humidity. However, lacquer hybridized with the other silane listed in Table I did not dry at $20-25^{\circ} \mathrm{C}$ and $45-50 \%$ relative humidity. A high relative humidity $(70-75 \% \mathrm{RH})$ is the optimum condition for laccase to catalyze the monomer of urushiol into a dimer, trimer or oligomer, and the drying process proceeds as an enzymatic polymerization. In low humidity (less than $50 \% \mathrm{RH}$ ), water in the lacquer sap evaporated in a low vapor pressure. Because the diffusion and osmosis of oxygen turn hard, the reduced $\mathrm{En}-\mathrm{Cu}^{+}$in laccase is not oxidized to $\mathrm{En}-\mathrm{Cu}^{++}$, and the polymerization of laccase could not continue. However, in the hybrid lacquer, the reaction between urushiol and the silicone compound occurred even at

Table II. Drying properties of lacquer with $2 \mathrm{wt} \%$ organic functional silane at $20-25^{\circ} \mathrm{C}$ and $70-75 \% \mathrm{RH}$

\begin{tabular}{lccccc}
\hline $\begin{array}{c}\text { Material } \\
\text { [No. (Classification)] }\end{array}$ & pH & DF & TF & HD & Discoloration \\
\hline Blank K-0 & 4.28 & $3: 50$ & $4: 40$ & $6: 30$ & Light \\
S-1 (Vinyl silane) & 4.92 & $3: 50$ & $4: 40$ & $6: 30$ & Light \\
S-2 (Amino silane) & 5.82 & $4: 00$ & $5: 00$ & $7: 00$ & Deep \\
S-3 (Amino silane) & 5.53 & $3: 00$ & $3: 50$ & $5: 20$ & Deep \\
S-4 (Amino silane) & 6.97 & - & - & ND & - \\
S-5 (Epoxy silane) & 4.88 & $3: 45$ & $4: 35$ & $6: 30$ & Light \\
S-6 (Epoxy silane) & 4.69 & $3: 15$ & $4: 45$ & $6: 30$ & Light \\
S-7 (Epoxy silane) & 5.04 & $2: 30$ & $4: 45$ & $5: 30$ & Light \\
S-8 (Methacryl silane) & 4.48 & $3: 15$ & $4: 35$ & $6: 30$ & Light \\
S-9 (Methacryl silane) & 4.91 & $3: 15$ & $4: 35$ & $6: 30$ & Light \\
S-10 (Phenyl silane) & 5.00 & $3: 50$ & $4: 50$ & $6: 30$ & Light \\
\hline
\end{tabular}

DF: Dust-free dry, TF: Touch-free dry, HD: Hardened dry, ND: Non-drying. low humidity (Scheme 2). ${ }^{12}$ As the hydroxyl group in urushiol was consumed, the anti-oxidization of urushiol decreased; when the urushiol monomer in the lacquer sap was less than $30 \%$, autoxidation of the olefin in the side chain of urushiol was initiated, and then a high polymer was formed. ${ }^{13,14}$ The hybrid lacquer film not only has a fast drying time but also has high pencil hardness $(8 \mathrm{H}$ for a film dried one month) and strong UV light and water resistances.

It was considered that amino silane could reduce the hydrogen-ion density in lacquer sap due to the amino residues and promote enzyme polymerization, but the same amino silane S-2, delayed drying of the kurome lacquer. When lacquer was hybridized with S-4, it failed to dry, suggesting that among the alkoxy groups, the activity of methoxy was higher than that of ethoxy, and trimethoxy was higher than dimethoxy. Considering the effect of the amino group, it was considered that the results originated from the different speed of the hydrolysis and alcoholysis steps.

Moreover, because the non-conjugated double bond absorption of triene at $982 \mathrm{~cm}^{-1}$ decreased or disappeared and the absorption of the conjugated double bond of triene at $993 \mathrm{~cm}^{-1}$ appeared strongly while the $1476 \mathrm{~cm}^{-1}$ decreased and the absorption of the ether combination of urushiol at $1465 \mathrm{~cm}^{-1}$ appeared in the IR spectra of lacquer hybridized with S-7, as shown in Figure 1, it was considered that the quinone produced from oxidization of urushiol by laccase attacked the epoxy ring that was opened and oxidization of the side chain occurred, which then caused the bridge construction reaction. It was known that the solid structure of the side chain would change with the addition of oxygen or carbon as in Scheme $1 .{ }^{15}$

The high drying promotion effects of S-3 and S-7 were tested at different proportions. The results are shown in Table III. As the ratio of organic silicone compound to lacquer sap increased, the monomer decreased and the oligomer and polymer increased, suggesting that a reaction between urushiol and the silicone compound had occurred. Kurome lacquer hybridized with amino silane S-3 increased remarkably in viscosity with the generation of heat, and dried

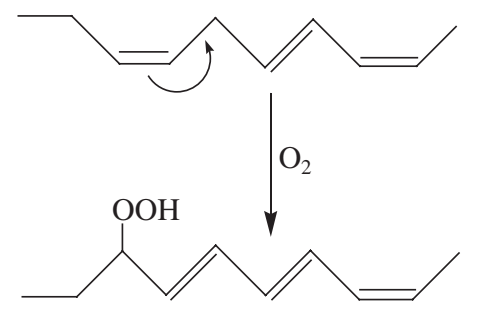

Scheme 1. Change from non-conjugated to conjugated structure of triene in side chain of urushiol on addition of oxygen from the atmosphere. 


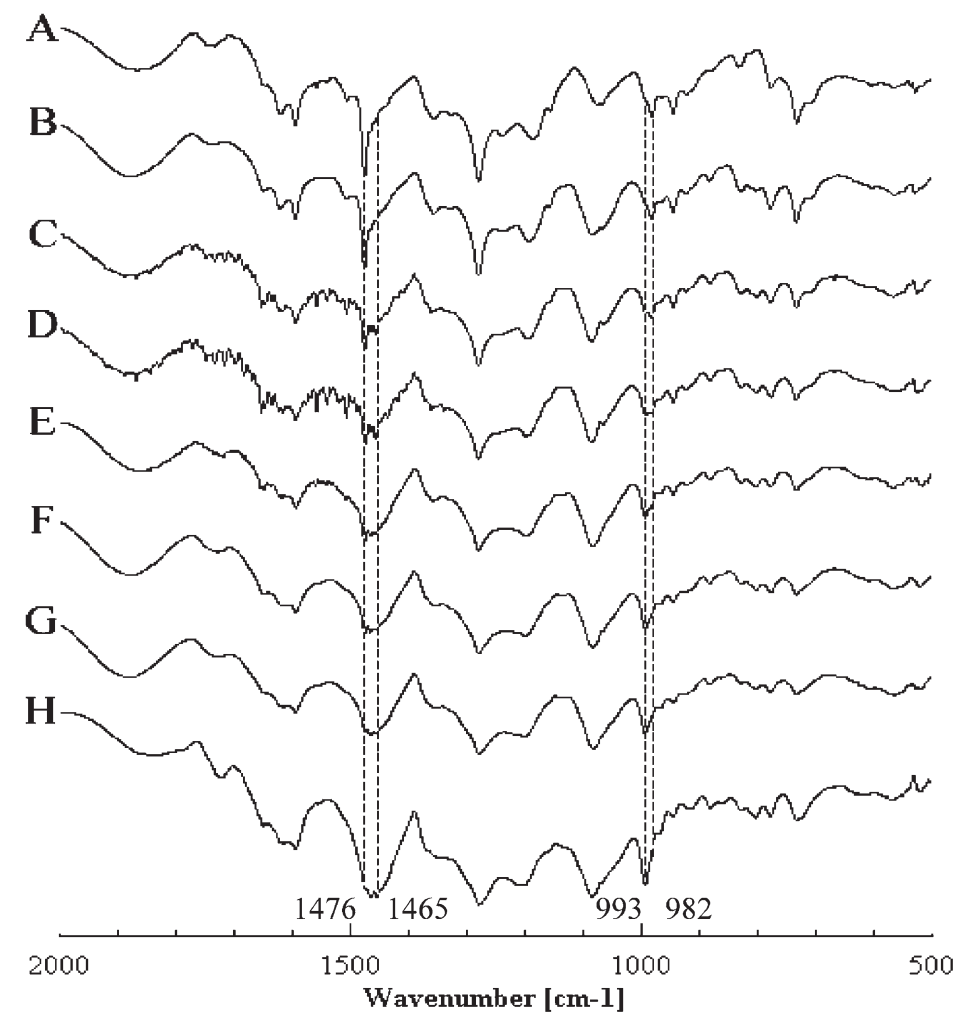

Figure 1. IR spectra of blank kurome lacquer k-0 (A), and lacquer hybridized with S-7 dried in $0 \mathrm{~h} \mathrm{(B),} 1 \mathrm{~h} \mathrm{(C),} 2 \mathrm{~h}$ (D), $5 \mathrm{~h}$ (E), $8 \mathrm{~h}(\mathrm{~F})$, $1 \mathrm{~d}(\mathrm{G})$, and $2 \mathrm{~d}(\mathrm{H})$.

Table III. Properties of kurome lacquer hybridized with different amounts of amino silane

\begin{tabular}{|c|c|c|c|c|c|c|c|c|c|c|c|c|}
\hline \multirow{2}{*}{$\begin{array}{l}\text { Lacquer } \\
\text { property }\end{array}$} & \multicolumn{6}{|c|}{ Amount of S-3 added } & \multicolumn{6}{|c|}{ Amount of S-7 added } \\
\hline & 0.0 & 0.5 & 1.0 & 1.5 & 2.0 & 3.0 & 0.0 & 1.0 & 3.0 & 5.0 & 7.5 & 10.0 \\
\hline Viscosity $^{\mathrm{a}}$ & 2543 & 2647 & 2825 & 3587 & 3966 & 5117 & 2637 & 2520 & 2354 & 2020 & 1810 & 1789 \\
\hline $\mathrm{DF}^{\mathrm{b}}$ & $3: 50$ & $3: 00$ & $3: 00$ & $2: 50$ & $3: 00$ & $2: 30$ & $3: 50$ & $3: 00$ & $2: 40$ & $2: 40$ & $2: 30$ & $3: 00$ \\
\hline $\mathrm{TF}^{\mathrm{b}}$ & $4: 40$ & $4: 00$ & 4:00 & 4:00 & $3: 50$ & $3: 20$ & $4: 40$ & $3: 50$ & $3: 30$ & $3: 30$ & $3: 00$ & $3: 00$ \\
\hline $\mathrm{HD}^{\mathrm{b}}$ & $6: 30$ & $5: 30$ & $5: 30$ & $5: 30$ & $5: 20$ & $4: 30$ & $6: 30$ & $5: 30$ & 5:00 & $5: 00$ & $4: 30$ & $5: 00$ \\
\hline Monomer (\%) & 74.35 & 71.75 & 71.23 & 71.23 & 71.75 & 67.65 & 76.36 & 78.30 & 76.92 & 77.59 & 69.32 & 65.42 \\
\hline Oligomer (\%) & 23.64 & 26.43 & 27.51 & 25.95 & 23.84 & 30.10 & 23.64 & 20.39 & 20.56 & 19.28 & 23.52 & 19.07 \\
\hline Polymer (\%) & 0.00 & 0.97 & 1.00 & 1.26 & 1.82 & 2.00 & 0.00 & 1.30 & 2.52 & 3.13 & 7.16 & 15.51 \\
\hline
\end{tabular}

${ }^{\mathrm{a}} \mathrm{mPa} / \mathrm{s}$, at $20^{\circ} \mathrm{C}$, ${ }^{\mathrm{b}}$ Drying at $20^{\circ} \mathrm{C}, 70-75 \% \mathrm{RH}$, drying time, h:min.

faster at $20^{\circ} \mathrm{C}$ and $70-75 \% \mathrm{RH}$ compared to the blank $\mathrm{K}-0$. On the other hand, epoxy silane S-7 promoted lacquer sap drying best without either a viscosity increase or heat generation.

Because it has also been considered that amino silane can isomerize the double bond in the side chain of urushiol from a non-conjugated form to a conjugated form, we tested the addition of amino silane S-3 to urushiol and linseed oil separately and found that urushiol generated heat and increased in viscosity, but linseed oil did not generate heat and the viscosity decreased. The results are summarized in Table IV.

The results shown in Table IV reveal that an organic functional silane with the structure of $N$ - $(\beta$-amino ethyl)- $\gamma$-amino propyl trimethoxy silane can generate
Table IV. Change in viscosity $\left(20^{\circ} \mathrm{C}, \mathrm{mPa} / \mathrm{s}\right)$ after addition of amino silane S-3

\begin{tabular}{lrrr}
\hline \multirow{2}{*}{ Materials } & \multicolumn{3}{c}{ Quantity of amino silane S-3 added } \\
\cline { 2 - 4 } & $0 \%$ & $2 \%$ & $5 \%$ \\
\hline Urushiol & 1015 & 1591 & 3610 \\
Linseed oil & 136 & 104 & 84 \\
\hline
\end{tabular}

heat because it acts on the phenol-type hydroxyl group of urushiol, and the alcoholysis reaction occurs rapidly. As mentioned above, epoxy silane was oxidized by opening the epoxy ring, and the molecular weight changed considerably with the increased addition of silane. However, silane also diluted the lacquer sap and caused the lacquer to hybridize with epoxy silane 


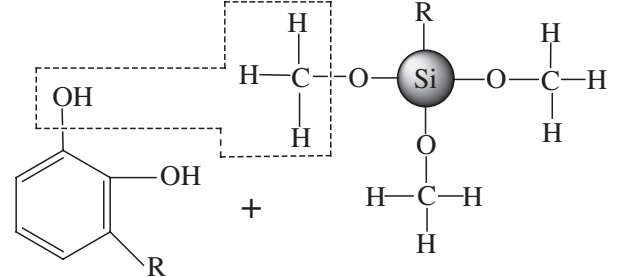

Scheme 2. Alcoholysis of urushiol and organic functional silane.

to produce low viscosity. The reaction is shown in Scheme 2.

Generation of Hybrid Lacquer using a Mixture of an Organic Functional Silane and Lacquer Sap

In order to establish an organic-inorganic polymer network using lacquer sap and an organic functional silane, we combined equal amounts of the highly reactive silane S-3 and S-7 and then added them to kurome lacquer K-0 to obtain a hybrid lacquer. Figure 2 is a photo of the drying time of the hybrid lacquers measured in an automatic drying time at $20-25^{\circ} \mathrm{C}$ and $45-55 \%$ RH. The drying results are summarized in Table V.

Dryness was promoted by increased concentration of amino and epoxy silane compounds. With a 1:1 ratio, hardening dryness was achieved within six and a half hours, but with 100:80, it required $25 \mathrm{~h}$. These changes in low relative humidity $\left(20-25^{\circ} \mathrm{C}, 45-\right.$ $50 \% \mathrm{RH}$ ) were unlikely to be based on enzyme polymerization but were probably due to the organicinorganic polymer hybrid.

The results shown in Table $\mathrm{V}$ also revealed that a $5 \mathrm{wt} \%$ addition of the organic silane compound produced a suitable viscosity, good molecular weight distribution, and the best drying time in natural and low humidity environments. The change in the lacquer film with time at normal temperature with the above-mentioned 1:1 combination hybrid lacquer was examined by IR spectra, and the result is shown in Figure 3.

Immediately after mixing, the IR spectra of hydroxyl groups of urushiol at $3500 \mathrm{~cm}^{-1}$ decrease, and absorption of the cyclohexanepoxide combination appears clearly at $780-830 \mathrm{~cm}^{-1}$ and siloxane at 1100 $\mathrm{cm}^{-1}$. These absorptions were amplified further after $1 \mathrm{~h}$ and then stabilized in advance of a reaction. The absorption of aromatic amine appears at $1290 \mathrm{~cm}^{-1}$ after one week, ${ }^{16}$ suggesting that the amino group has combined with the core of urushiol.

Moreover, it is possible that the amino group of S-3 can cause the ring-opening of epoxy S-7 to occur, and produce a mesh net-work structure with mutual penetration. Because the alcoholysis reaction occurred be-

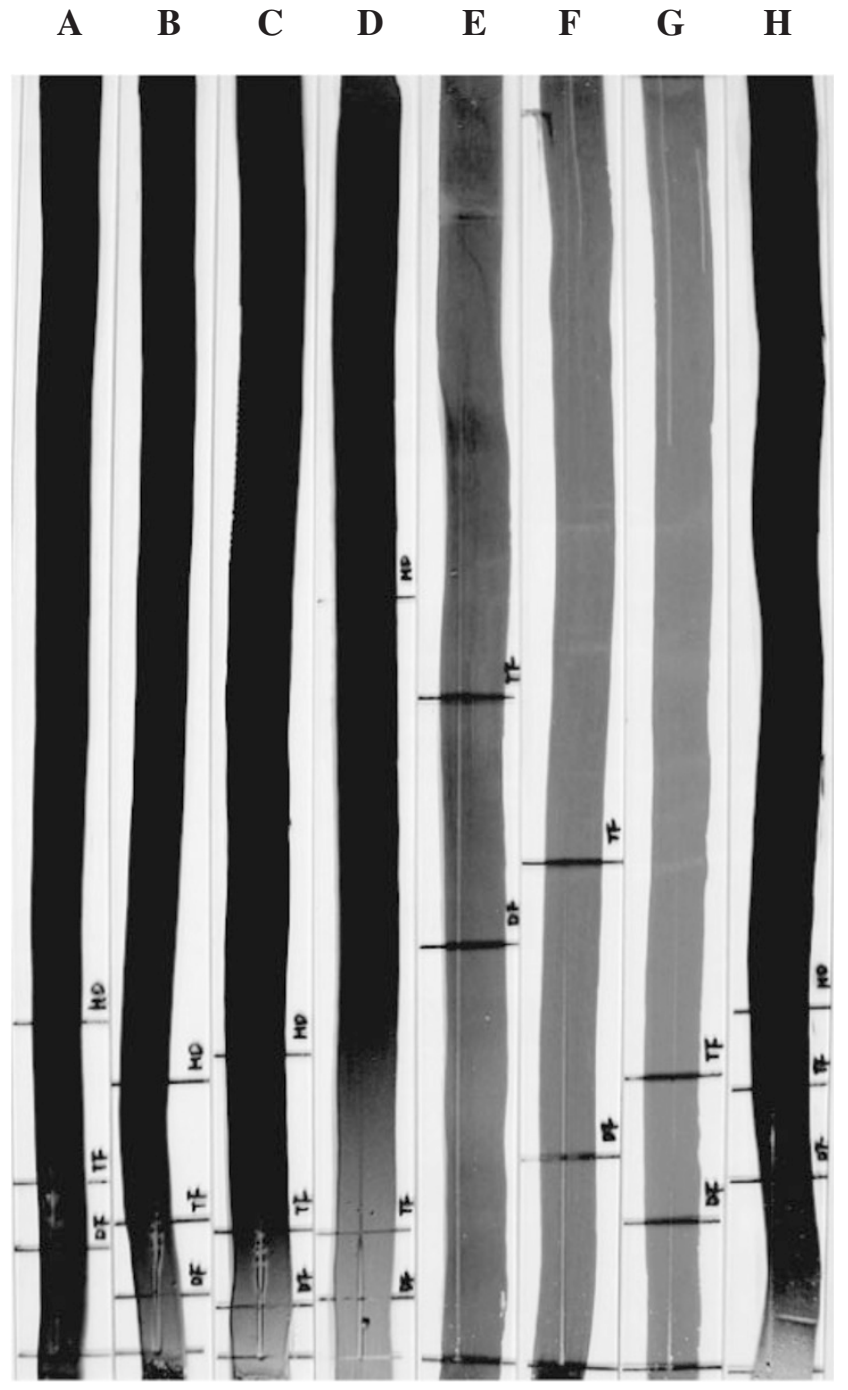

Figure 2. Photos of hybrid lacquers, lacquer:silane $=(\mathrm{A})$ $100: 2$, (B) 100:5, (C) 100:10, (D) 100:20, (E) 100:40, (F) 100:60, (G) 100:80, and (H) 100:100.

Table V. Change in drying property with combination of kurome lacquer and S-3/S-7 mixture

\begin{tabular}{ccccr}
\hline \multirow{2}{*}{$\begin{array}{c}\text { Kurome } \\
\text { lacquer }\end{array}$} & S-3/S-7 silane & \multicolumn{3}{c}{$\begin{array}{c}\text { Drying property (h:min) } \\
\text { at } 20-25{ }^{\circ} \mathrm{C}, 45-55 \% \mathrm{RH}\end{array}$} \\
\cline { 3 - 5 }$(\mathrm{g})$ & $\mathrm{g})$ & $\mathrm{DF}$ & $\mathrm{TF}$ & $\mathrm{HD}$ \\
\hline 100 & 0 & \multicolumn{3}{c}{ None drying } \\
100 & 2 & $2: 00$ & $3: 10$ & $6: 10$ \\
100 & 5 & $1: 00$ & $2: 20$ & $5: 00$ \\
100 & 10 & $1: 00$ & $2: 20$ & $5: 40$ \\
100 & 20 & $1: 00$ & $2: 25$ & $13: 50$ \\
100 & 40 & $7: 40$ & $12: 00$ & $40: 00$ \\
100 & 60 & $3: 50$ & $9: 10$ & $30: 00$ \\
100 & 80 & $2: 50$ & $5: 20$ & $25: 00$ \\
100 & 100 & $3: 30$ & $5: 00$ & $6: 30$ \\
\hline
\end{tabular}

tween the alkoxy residue of the organic polysiloxane and the hydroxyl group of urushiol, it can be surmised that a high polymer lacquer film was formed from the 


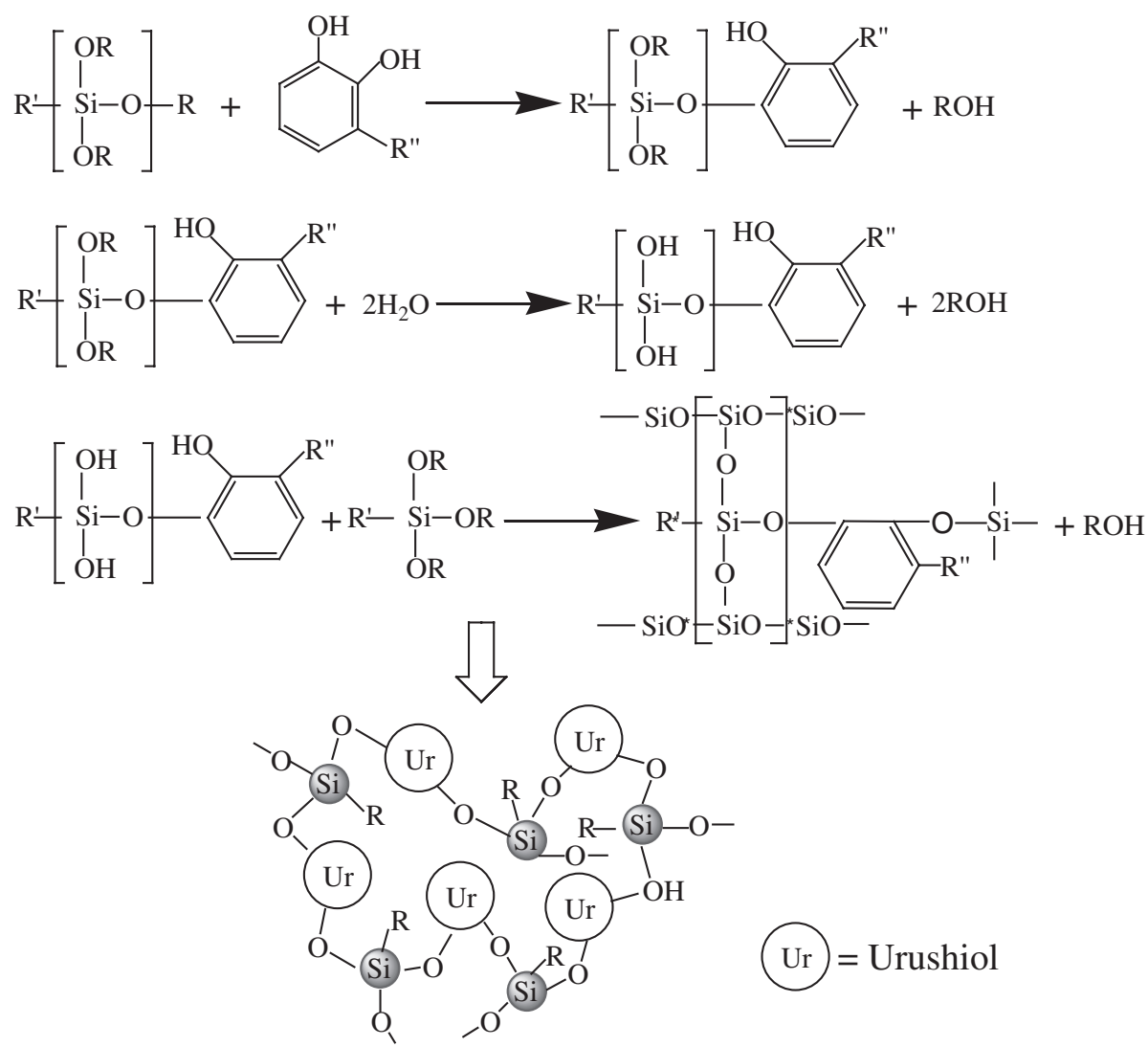

Scheme 3. Alcoholysis between urushiol and organic silane.

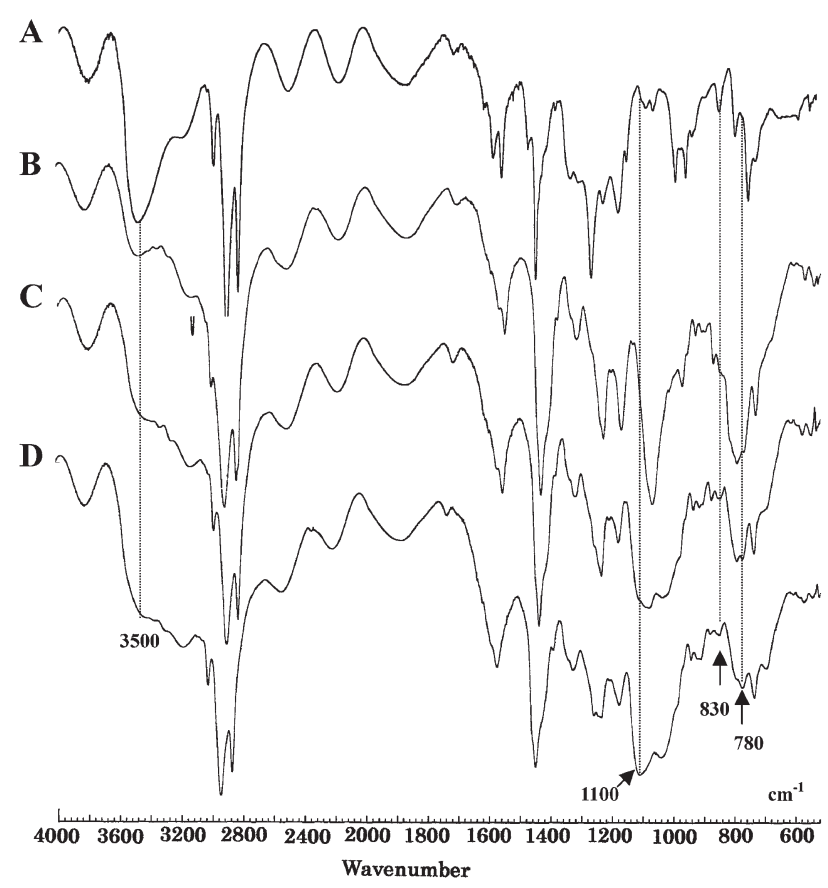

Figure 3. IR spectra of blank kurome lacquer k-0 (A), hybrid lacquer dried in $0 \mathrm{~h}(\mathrm{~B}), 1 \mathrm{~h}(\mathrm{C})$, and 1 week (D).

three-dimensional bridge construction by repetition of the $\mathrm{Si}-\mathrm{O}$ combination. The reaction image is shown in Scheme 3.

\section{CONCLUSIONS}

Lacquer is the only known natural material that is polymerized by an enzyme, laccase, to yield a beautiful surface coating. Laccase is a copper-glycoprotein and functions as the polymerization catalyst of urushiol so that the activity of the laccase that is polymerizing urushiol significantly affects the rate of drying. In order to maintain the optimal laccase activity, a high relative humidity $(70-90 \% \mathrm{RH})$ is required for the polymerization of urushiol. Lacquer has been used only in crafts until now because of the strict drying conditions required. For example, maintenance of a fixed temperature and about $80 \%$ humidity requires a special room (lacquer chamber) in which to dry the lacquer. Thus, management of the drying process is difficult. For this reason, we tried adding an organic functional silane to lacquer sap to obtain a new hybrid lacquer that will dry in natural conditions.

Amino and epoxy silane with the structure of $N-(\beta-$ amino ethyl) $-\gamma$-amino propyl trimethoxy silane and $\beta$ (3,4-epoxy cyclohexyl ethyl trimethoxy silane had a fast alcoholysis reaction with urushiol and were understood to induce remarkable promotions of polymerization. Moreover, the amino residue opened the ring of the epoxy residue and reacted with urushiol. 
Based on IR spectra, it can be inferred to build a mesh net-work structure with mutual penetration. Furthermore, it is possible that the hybrid lacquer film can also prevent degradation by ultraviolet rays, and this will be studied in future research.

Acknowledgment. The authors are deeply grateful to Mr. K. Nagase for his good ideas and advice, and would like to dedicate this paper to his memory. This work was partially supported by the New Energy and Industrial Technology Development Organization (NEDO) of Japan.

\section{REFERENCES}

1. J. Kumanotani, Prog. Org. Coat., 26, 163 (1995).

2. T. Terada, K. Oda, H. Oyabu, T. Asami, "Urushi-the Science and Practice," Rikou Publisher, Tokyo, Japan, 1999.

3. Y. Chujo and T. Saegusa, Adv. Polym. Sci., 100, 11 (1992).

4. Y. Chujo, Polym. Mater. Encycl., 6, 4793 (1996).
5. Y. Chujo, Curr. Opin. Solid State Mater. Sci., 1, 806 (1996).

6. JIS K 5950.

7. F. Fleury, Recherches Sur La Laccase (1924).

8. K. Kadokura, Biochem. Z., 224, 292 (1930).

9. Toshiba silicone \& Shin-Etsu silicone catalogs, Japan.

10. T. Miyakoshi, K. Nagase, and T. Yoshida, "Progress in Lacquer Chemistry," IPC, Japan, 1999, p 43.

11. R. Lu, S. Harigaya, T. Ishimura, K. Nagase, and T. Miyakoshi, Prog. Org. Coat., 51, 238 (2004).

12. J. Gan, "Urushi Chemistry," Chinese Academy of Science, Beijing, 1984.

13. K. Nagase, R. Lu, and T. Miyakoshi, Chem. Lett., 33, 90 (2004).

14. K. Nagase, Y. Kamiya, K. Hodumi, and T. Miyakoshi, Nippon Kagaku Kaishi, 377 (2002).

15. R. Oshima, Y. Yamauchi, C. Watanabe, and J. Kumanotani, J. Org. Chem., 50, 2613 (1985).

16. R. Silverstein and F. Webster, "Spectrometric Identification of Organic Compounds," 6th ed., Tokyo Kagaku Dojin, Tokyo, 1999, p 107. 